\title{
Assessment of Seismic Indirect Losses Based on Utility Curves
}

\author{
Jaime García-Pérez¹, Eric García-López² \\ ${ }^{1}$ Instituto de Ingeniería, Ingeniería Estructural, Edif. 2, Universidad Nacional Autónoma de México, Ciudad Universitaria, \\ Coyoacán, Mexico \\ ${ }^{2}$ National Institute of Criminal Sciences, Tlalpan, Mexico \\ Email: jgap@pumas.ii.unam.mx, eric.garcia@inacipe.gob.mx
}

How to cite this paper: García-Pérez, J. and García-López, E. (2019) Assessment of Seismic Indirect Losses Based on Utility Curves. Open Journal of Civil Engineering, 9, 211-229.

https://doi.org/10.4236/ojce.209.93015

Received: July 30, 2019

Accepted: September 7, 2019

Published: September 10, 2019

Copyright (c) 2019 by author(s) and Scientific Research Publishing Inc. This work is licensed under the Creative Commons Attribution International License (CC BY 4.0).

http://creativecommons.org/licenses/by/4.0/

\section{(c) (i) Open Access}

\begin{abstract}
In the process of quantifying optimum seismic design parameters, the losses implying the failure of the system must be assessed. Intangibles such as human lives may lie among indirect losses. In this paper, we propose a model to calculate the value of the investment that society should be willing to make for saving lives. In order to do this, we analyze both individual and social problems. However, special treatment is given to the individual problem where the value of the life of a human being is inferred by what the person should be willing to pay or willing to accept to reduce the risk of dying. Due to the use of utility curves in the calculation of this kind of intangible, we pay special attention to shape and requirement conditions of these curves. We also pay attention when personal impact and legacies or bequests are considered in utility curves. The results are shown through some applications, especially in the computation of optimum seismic design coefficients at a low seismicity site.
\end{abstract}

\section{Keywords}

Indirect Losses, Human Life Value, Willingness Criteria, Utility, Seismic Design

\section{Introduction}

In order to optimize reliability in earthquake engineering, we try to maximize the utility associated with the design of the system involved. This utility takes into account the benefit resulting from the existence of the system, the losses implying its possible failure, and its initial cost. Therefore, we aim to select a seismic design parameter so that an objective function is optimized [1] [2]. In 
the process of computing the losses, we must often assess the value of intangibles. Human lives may lie among these intangibles. But how, in practice, can a civil engineer or a decision-maker find the optimum solution if he lacks a formal, quantitative treatment to assess the most important element that it would be lost in case of failure-human lives? He needs an answer no matter how debatable it is, or how unacceptable it may seem to those who judge him. This circumstance has led to this study.

One can find several methods and techniques in the literature that allow for obtaining the optimum solution in rational decision-making if the relation is known between utility, on the one hand, and benefits, resources, and losses on the other hand. In many problems, the magnitude of benefits, expenditures and losses are small enough, thus, it is valid to assume that the utility is a linear function thereof. However, when human lives are in play, losses usually are so high that this hypothesis is invalid and it is necessary to define the shapes of the utility curves. The criteria proposed in the literature to assess an intangible such as human life lead to results so dissimilar that a reliable criterion is lacking.

The meaning that we give here to the term human life value is that of how much a person or a society is willing to invest for preserving a life. The enshrinement of life (the life in all its forms) though still deprived of metaphysical contents is a good raison de être. However, any time that we receive overtime wages for carrying out a job where we are at risk, regardless of how small it is, any time that we decide how safe to make a civil engineering work, and how much to invest in medical and sanitary actions, we are implicitly assigning values to the human life. Therefore, the value of human life implies computing the value of one's life, of someone else's life or the value that society and the government assign to the lives of its members. These three types of values differ among them and pose problems of a different kind. It is advisable to do this rationally and choose the optimum solution from the decision-making point of view.

The main approaches that have dealt with the topic of human life are: human capital, consumption and its variations, gross domestic product per capita, willingness to accept risks and willingness to pay to avoid them as well as how the willingness criteria are combined with human capital, considerations of possible legacies or bequests, considerations of possible life insurance, capital and workforce, social and personal impacts, and quality of life.

García-Pérez [3] reviews these approaches and pays special attention to the human capital approach, where an anonymous life value is taken as the expected present value of a person's contribution to the gross domestic product, throughout the rest of his/her life. The author also postulates a simple utility curve later used to calculate the factor by which one has to multiply the value given by the human capital approach in order to obtain the value that a person would assign to his/her life.

The main objection to the human capital approach and its variations is that 
they only consider the economic side of the problem. Moreover, they consider the perfection of the job market and, as we know, the job market is never and has never been perfect. Adopting the perfection hypothesis seriously distorts the results for individual cases. It suffices for unemployment to exists, regardless of how small it is, so that a worker is replaceable, and sometimes without decreasing production or just with a partial reduction thereof. Therefore, the value of some lives becomes zero, or it undergoes an enormous reduction if we correct how the income of the unemployed is taken into account, while the value of others is reduced to a greater or lesser extent, depending on the possibility of replacement. We could extend ourselves by pointing out other imperfections of the job market and its consequences, but let us not delve into the matter.

Whether the value of a single life is of interest for society or for the owner of that life, we must disregard the human capital approach and its variations despite how much they have been used, even in recent times. We must instead turn to the possibility of inferring the value that each one assigns to his/her own life when he/she tries to face a specific increase in risk in exchange for an economic compensation, or of an expenditure made to decrease a specific risk of losing life. In this paper, we will adopt this latter criterion, and since it uses utility curves, we pay special attention to them. Furthermore, we proceed according to utilitarianism. The topic is essential to better designs (not only from designer's point of view but also from decision-makers side) and even developing modern seismic codes. All of this is discussed in the following sections.

The paper starts by discussing how much society should be willing to invest for saving lives, considering several factors and from an individual and social point of view. Then we describe some concepts of utility theory which are used later in the calculation of the value of human life. Finally, we describe the optimization process in the computation of seismic design coefficients, and show some examples.

\section{Individual and Social Problems}

In both individual and social problems, the conflict arises between the scale of values of the decision-maker and the one of his client, either a person or society. From the normative point of view, we may demand that the decision-maker adopt absolute ethics consisting of maximizing the sum of the felicities of all sentient beings from here to eternity [4] [5]. In all cases, the criteria applied by the decision-maker will be the result of negotiations between absolute ethics and the interests of the client. With regard to individual problems, the negotiation is between absolute ethics and the maximization of the expected present value of the felicity of the individual. A linear combination of the felicities of other beings will be internalized in this felicity. Social problems will be negotiated with the expected present value of the sum of felicities of those forming society, affected by the degree to which each individual belongs to society. Again, other beings' felicities will be internalized in a linear combination thereof. In the first type of 
problem, the value of a life of a human being is inferred from what he should be willing to pay for reducing a risk of dying or of what risk he should be willing to assume in return for a compensation. In the second type, ethics require the decision-maker to put himself/herself conceptually in the circumstances of each member of society.

\subsection{Individual Value of Life}

Let us first consider the case of a person taking a risk of losing his/her life in a short time in a single event in exchange for a compensation. We define the value of his/her life as the ratio of the compensation to the probability of dying in a transaction that the person would make if he/she were rational. We infer the risk by assigning a value to the compensation and solving the probability of dying that would make the person indifferent between his/her current situation and the transaction. In other words, the expected utilities in both situations must be the same [6]. We compute similarly the value of life inferred from a situation in which the person is willing to pay a specific quantity in exchange for reducing the probability of dying in a short time by a certain amount. We define the value of his/her life as what he/she is willing to pay divided by the reduction of the probability of dying and again we infer the corresponding quantities equating the utilities in his/her current situation and in case of accepting the transaction [6].

\subsection{Social Value of Life}

From society's point of view, we want the expected present value of its members' utilities in their current situation to equal that corresponding to a second state in which society invests resources or receives a benefit in exchange for decreasing or increasing, respectively, the probability of one or more of its members dying. If the possibility that everyone has of enjoying the resources of society, was independent from the number of inhabitants, then the consideration that the decision-maker must proceed as if he had the same probability of putting himself/herself in the circumstances of each member of society (probability affected by the degree in which each individual belongs to society) would lead to the value of an anonymous life. This value would be the average (weighted by the degrees in which an individual belongs to society) of the individual values of all members increased by the corresponding value of the social impact [4] [5].

\section{Utility and Felicity}

Utility is the logical measure of the intensity of preference that satisfies the axiom of von Neumann and Morgenstern [7] which makes utility synonymous with expected utility. To be clear we will refer first to preferences in the sense that what we ought to morally prefer.

Let us make $\succ$ the relation of preference so that if $A$ and $B$ are two possible states, then $A \succ B$ means that $A$ is preferred over $B$ for the individual under 
study. It is possible to understand "is preferred" in a descriptive sense, as "the individual behaves as if he prefers", in a subjective sense as "the individual feels as if he prefers", or in the normative sense as "the individual must prefer". For the sake of brevity, we will say that $A \succ B$ means that the individual prefers $A$ over $B$, in the understanding that the symbolic expression accepts the three meanings. Likewise, let us make $\prec$ and $\sim$ be the does not prefer and indifference relations respectively. That is, $A \prec B$ means that the individual does not prefer $A$ over $B$, and $A \sim B$ that he is indifferent between these two states.

Let us consider a set of $P$ possible states, $\left\{m_{i}\right\}, i=1, \cdots, p$. Let us assume that they form a completely ordered set with respect to the preference relation. This means that for all $i$ and all $j$, it is necessary that $m_{i} \succ m_{j}$ or $m_{i} \prec m_{j}$. In other words, $m_{i} \succ m_{j}, m_{i} \sim m_{j}$, and the transitivity relation is met, that is, if $m_{i} \succ m_{j}$ and $m_{j} \succ m_{k}$ then $m_{i} \succ m_{k}$. Under these circumstances, $U_{i}$ is the utility of state $m_{i}$ and $U_{j}$ that of $m_{j}$ if and only if two conditions are met. The first is if $m_{i} \succ m_{j}$ is equal to $U_{i}>U_{j}$, and consequently $m_{i} \prec m_{j}$ is equal to $U_{i}<U_{j}$, and $m_{i} \sim m_{j}$ is equal to $U_{i}=U_{j}$. Second, if $m$ means that states $m_{1}, \cdots, m_{p}$ can occur with respective probabilities $Q_{1}, \cdots, Q_{p}$ then the utility of $m$ is $U=E\left[U_{i}\right]=\sum_{i}^{p} Q_{i} U_{i}$ where $E$ stands for expected value.

To assign numerical values to utility, we can proceed as follows: first, we reorder the states $m_{i}$ so that the intensity of preference is non-decreasing with $i$, so $m_{1} \prec m_{2} \prec \cdots \prec m_{p}$. If $m_{1} \sim m_{p}$ we assign any value to all $U_{i}$ independent from $i$. If $m_{p} \succ m_{1}$, we assign arbitrary values to $U_{1}$ and $U_{p}$ dependent only on that $U_{1}<U_{p}$. Then we present the person with the possibility of participating in a lottery $I$, in which with probability $R$, he/she will be in the state $m_{1}$ and with probability $1-R$ in the state $m_{p}$, and we ask him/her to express his/her preference between the state $m_{i}$ and the lottery. Now, we vary $R$ up to $m_{i} \sim I$. Let $R_{i}$ be the value of $R$ for which the person is indifferent between $m_{i}$ and the lottery. Therefore, $U_{i}=R_{i} U_{1}+\left(1-R_{i}\right) U_{p}$, since the utility of $I$ is the second member of this equation according to the von Neumann and Morgenstern axiom. On the other hand, utility is uniquely defined by a positive linear transformation, which is evident when we observe that we choose $U_{1}$ and $U_{p}$ arbitrarily without further condition than $U_{p}>U_{1}$ if $m_{p} \succ m_{1}$ or $U_{p}=U_{1}$ if $m_{p} \sim m_{1}$.

Utility in the ordinary sense is an a priori measure, that is to say, before the experience of the states to which it is referred. Felicity in a quantitative sense is an a posteriori utility. It is posterior to the experience of the states, to which it is referred, and under the hypothesis that the person remembered his/her living experience perfectly. In decision-making, the expected value of felicity is a preposterior utility, that is, a measure of the intensity of preference that a person would have if he/she had experienced the concerned states, and assessed it before he/she experiences them. Utility measures the intensity of desire; felicity in a quantitative sense, the intensity as it is preferred to have experienced a state, and in decision-making, the expected value of felicity is the expected value of the 
intensity, as he/she would have preferred to have experienced.

Utility in the current situation is the result of the following concepts: The utility coming from economic factors, the utility as the felicity caused by non-economic factors, and the disutility coming from anguish of the possibility of dying. In the first utility it can be considered the utility coming from the consumption in exchange for spending, the utility coming from the amount of money inherited to relatives, and the utility due to the benefit that those relatives will receive from a life insurance.

\section{Utility Curves}

Calculation of an intangible as the value of human life requires knowledge of the shapes of the utility curves in function of the wealth and income of the persons whose life we are interested in. When we give to utility its usual meaning that of the intensity of desire, or the a priori preference, these curves must meet certain conditions [4] [5] [8]. These conditions apply to the derivative of utility with respect to time in function of income per unit time, as well as the utility in function of the total wealth including the expected present value of future incomes. We will express these curves as follows: $U=U(W)$ stands for the utility of wealth $W$, and $W_{\min }$ is the minimum value of $W$ to survive. Furthermore, $W$ and $U$ are expected present values of wealth and utility respectively. The aforementioned conditions are:

1) $U(W)=0$ if $W<W_{\min }$. This implies that the utility of a dead person is nil. It is arbitrarily imposed and by this, we accept either that $W$ includes the total wealth or that there is no unemployment insurance.

2) $U^{\prime}(W)>0$ if $W \geq W_{\min }$, where the prime denotes derivative with respect to $W$. If someone does not wish to receive an amount of money, he/she can donate the excess and remain as before.

3) $U^{\prime \prime}(W)<0$ if $W \geq W_{\min }$, that is, $U(W)$ is concave. People use the first incomes to cover the most urgent needs, thus they are the most valuable, and generally, the value of incomes decreases as wealth increases.

4) $U^{\prime \prime 2}(W)<U^{\prime}(W) U^{\prime \prime \prime}(W)$ if $W \geq W_{\min }$. This is equivalent to say that risk aversion, defined as $-U^{\prime \prime}(W) / U^{\prime}(W)$, must be a decreasing function of $W$. A person with a certain wealth is willing to accept certain risks and should be willing to accept the same risks and more with a greater wealth.

5) $U(\infty)=U_{\max }<\infty$. This condition comes from the finiteness of human beings. We are only able to desire with finite intensity. The unit value is often assigned to the maximum possible value.

6) $U(W)>0$ if $W \geq W_{\min }$. Although the misery of some people is such that they would rather be dead than alive, the opposite is also true.

\section{Functions}

In the literature, we can find some utility functions with different shapes such as exponential, logarithmic and quadratic. Keeney and Raiffa [8] and Howard [6] 
have proposed some utility functions to solve the problem. In this study, based on the functions posed by these authors and with small changes in the parameters, we will use two utility functions which comply with the requirements listed in the last section. The first function is shown in Figure 1 and is given by the following expression:

$$
U(W)=\left(1-\alpha_{1} \mathrm{e}^{-n_{1} \delta}\right) U_{\max }
$$

where, $\alpha_{1}$ and $n_{1}$ are constants, and $0<\alpha_{1}<1, U_{\max }$ is the maximum possible utility, assuming that we do not have any economic restriction, and $\delta=\left(W-W_{\min }\right) / W_{\min }$ is the normalized net wealth. We illustrate with two curves. The continuous graph is plotted with $\alpha_{1}=1$, and the discontinuous with $\alpha_{1}=0.5$, and both graphs with $n_{1}=0.1$ The second function is displayed in Figure 2 and is given by

$$
U(W)=\left(1-\alpha \mathrm{e}^{-a \delta}-\beta \mathrm{e}^{-b \delta}\right) U_{\max }
$$

where $\alpha, \beta$, and $b$ are constants, and $\alpha+\beta \leq 1$, and $\alpha \neq \beta$. The continuous plot employs $\alpha=0.1, \beta=0.9$, and the values for the discontinuous graph are $\alpha_{1}=0.1, \beta=0.4$. Both plots are for $a=0.01$, and $b=0.18$. Equation (1) is a particular case of Equation (2) corresponding to $a$ or $b=0$ or $\infty, \alpha$ or $\beta=0$, or $a=b$.

In Figure 1 and Figure 2, the continuous lines are for cases when $U_{\min }=0$ meaning that when income is so small that a person barely survives, he/she is unable to enjoy it at all. However, present knowledge accepts the hypothesis that, except for the neighborhood of $W_{\min }, U$ must be finite and not trivial. It is well

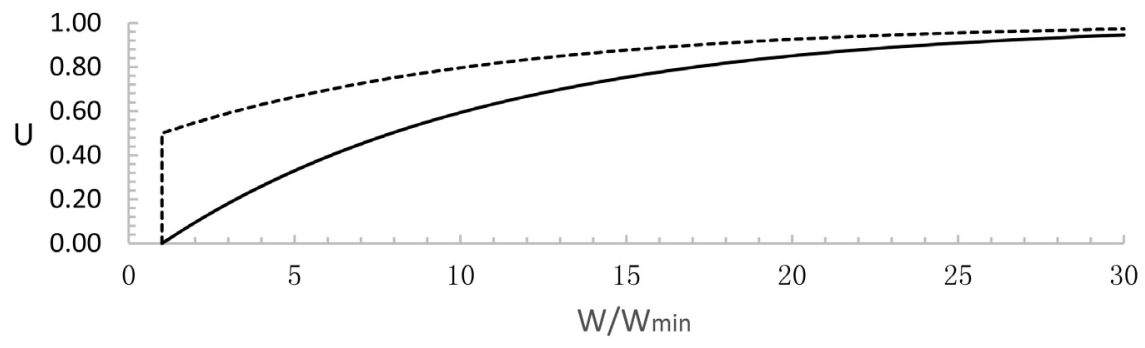

Figure 1. Utility function in Equation (1) with $U_{\min }=0$ (continuous) and 0.5 (discontinuous).

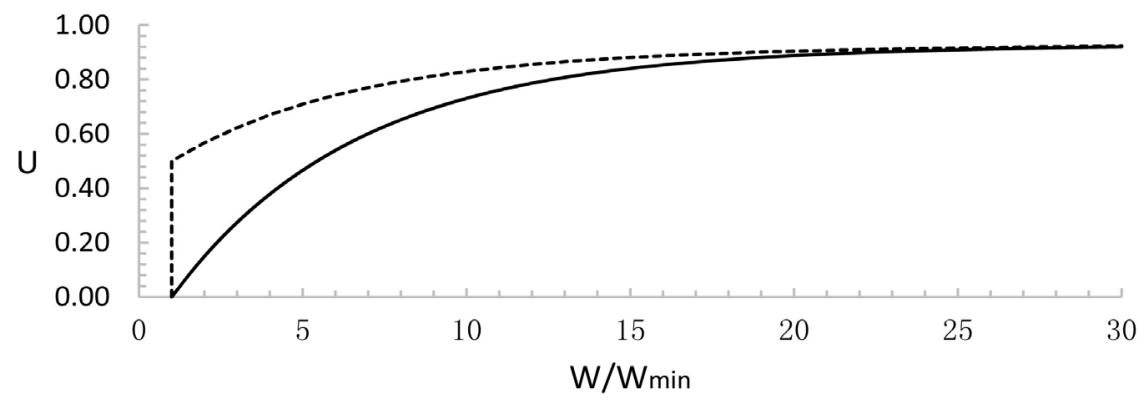

Figure 2. Utility function in Equation (2) with $U_{\min }=0$ (continuous) and 0.5 (discontinuous). 
known that noneconomic values are more prized than economic ones. The discontinuous lines are for cases when $U_{\min }=0.5 U$ following the results found by Rosenblueth [4]. Both figures have the upper limit $U_{\max }=1$ and start from $W / W_{\min }=1$.

\section{Willingness Criteria without Legacies or Bequests}

These approaches try to respond to the question "Would it not be good to ask those concerned how much they value their own life?" Stating the problem in this manner brings about the possibility of deducing the value that each one assigns to his/her own life when he/she tries to face a specific increase in risk in exchange for an economic compensation, or of an expenditure made to decrease a specific risk in losing one's life. We find in the literature some research done on this topic. Howard [6] examines the willingness to accept as well as the willingness to pay approach. We will take the results of this author in order to find the value which society is willing to invest for saving a life. Shepard and Zeckhauser [9] present a method which estimates utility and willingness to pay for a reduction in the risk of death at various ages. They also show that on a perfect market case willingness to pay is the sum of discounted expected future earnings and consumer surplus. Viscusi and Aldy [10] review more than sixty studies of mortality risk premiums and studies that present estimates of injury risk premiums. The authors also examine a variety of econometric issues, the role of unionization in risk premiums and the effect of age on the value of an anonymous life. The estimation of societal willingness to pay for safety is studied by Pandey and Nathwani [11]. The authors use the life quality index as a tool for the assessment of risk reduction initiatives that would support the public interest and enhance safety and quality of life.

\subsection{Willingness to Accept}

Howard [6] explains this approach as follows: Let us say that we offer a person a black pill warning him/her that if he/she swallows it, he/she has a probability $F$ of dying in a short time. We ask him/her for what amount of money he/she would be willing to swallow the pill. The person responds that for the quantity $E$. Therefore, he/she acts as if for him/her the value of his/her life were $L=E / F$ for him/her.

Consider now a person whose utility curve is known, then we ask him/her which economic compensation he/she would require to be willing to take a specific risk of losing his/her life. Let $U(W)$ be the utility associated with the expected present value of his/her future income and $E$ the compensation that he/she would require to undertake an activity with probability $F$ of dying. This sum must not be less than the one leading to a situation of indifference between his/her current state and the state associated with the risk and compensation [6], therefore $U(W)=(1-F) U(W+E)$. Whatever the shape of the expression provided by $U(W)$, we can assign values to $E$ and find the corresponding $F$. 
Once $E$ and $F$ are known we can attain the human value of life governed under these circumstances as $L=E / F$.

\subsection{Willingness to Pay}

Howard [6] now asks for the response to the problem of the white pill, that is, how much a person would be willing to be paid for swallowing a pill that eliminated a probability $F$ that the person had of dying in a short time. The approach is similar as in the willingness to accept with $(1-F) U(W)=U(W-E)$ and $L=E / F$ is still valid.

\subsection{Willingness for Small Risks}

When we deal with small risks, both approaches are indifferent and the limit of $L$ when $F$ tends to zero is given by the following expression [4] [5] [6].

$$
L=U / U^{\prime}
$$

We have presented the tool to deal with problems in which the probability of dying is high. In almost all the problems that we are interested in, however, that probability is very small. The mortality rates are between $10^{-5}$ and $10^{-6}$ per year [12] [13]. Thus, Equation (3) can be applied accurately, and we will use it in order to illustrate the willingness criteria in the examples bellow.

\section{Willingness Criteria Considering Legacies or Bequests}

One of the main reasons why a person saves is trying to cover uncertainties in his/her income. The wish of bequeathing to near relatives or to a cause that the person considers worthy explains just a part of the habit of saving. Thus, we will look at the amount of savings as a datum rather than trying to infer it from utility curves.

There are two types of problems in which we are interested in distinguishing between the utility of what a person consumes and the one associated to what he/she saves and would leave as a legacy to his/her loved ones. In the first type, it is about a unique event that will happen in a short time and in which the person can lose his/her life. In the second type, the probability of dying per unit time is affected, that is to say, the mortality rate that is relevant to the person. In problems of the first type, the person does not have time to modify his/her consumption unless he/she survives. If the person is willing to face a risk in exchange for certain compensation, this will be necessarily assigned to his/her heirs in case he/she dies.

In the case for legacies or bequests, the total utility is the expectancy of which the person assigns to the condition in which he/she survives at risk to that in which he/she dies, the latter determined by the utility that for the person under study represents the fact that his/her heirs enjoy his/her wealth. If the wealth of the person is $W$ having the dilemma of swallowing the black pill with the probability $F$ of dying in exchange for certain compensation or refuse the offer, his/her 
utility is given by

$$
U(W)=(1-F) U_{A}(W)+F U_{D}(W)
$$

where, $U_{A}(W)$ and $U_{D}(W)$ are the utilities corresponding to the states of nature of being alive or dead, respectively. Following Equation (3) we can write the value of human life for small changes in risk as $L=\left(U_{A}-U_{D}\right) /(1-F) U_{A}^{\prime}(W)+F U_{D}^{\prime}(W)$. Not only for the subtraction in the numerator, but also for the addition of $F U_{D}^{\prime}(W)$ to the denominator, this expression gives lower values than when the possibility of a legacy is not taken into account. We lack studies to define the shape of the utility functions $U_{D}$ and how to extend the result to conditions of an increase or decrease in the mortality rates.

\section{Personal Impact}

When a person dies, he/she not only loses his/her value of $U$, but an additional disutility is also present; this value has been called personal impact [4]. Without this impact, we are sure that humankind would not exist, since almost everyone goes through depressive states in which one would rather be dead, but finds something that prevents him/her from dying and saves his/her life. On the other hand, if the person would not die because of the decision, he would die some day from what we call a natural death, which will bring a deferred loss for personal impact. The net personal impact $I_{p}$ is obtained by subtracting the impact due to natural death from the personal impact, and it has been found that is roughly $U_{\min }$ [4]. Therefore, in terms of the expected present value of utility, the death of a person implies a total loss of $U+I_{p}$ for him/her. The value of human life for an individual when he/she has the option of receiving a compensation in exchange for assuming a small increase in risks is given by $L=\left(U+I_{p}\right) / U^{\prime}$ [4]. Figure 3 shows the net personal impact in a utility curve.

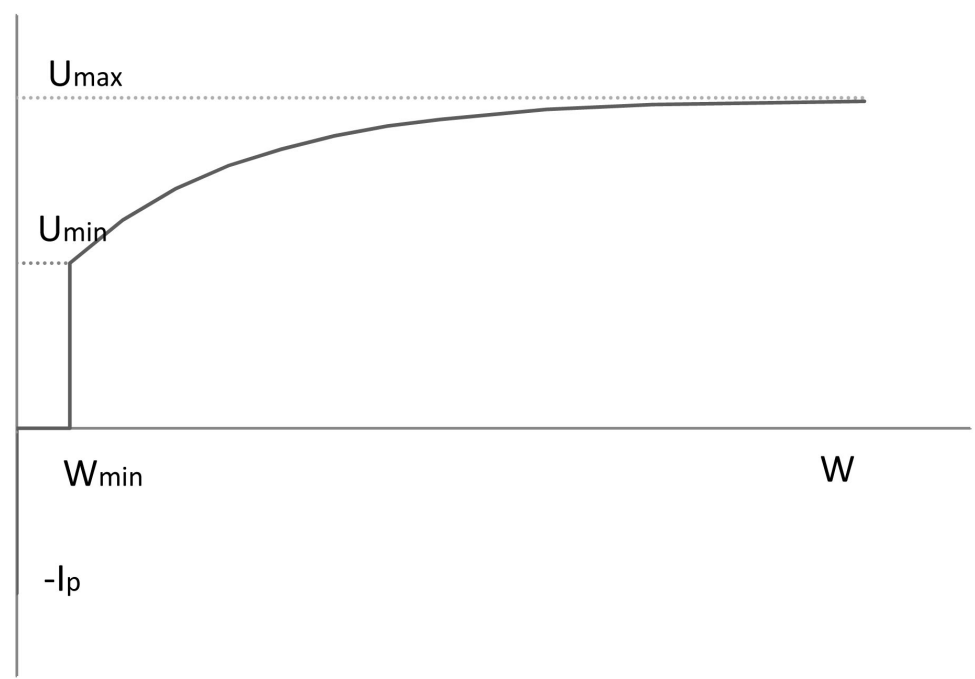

Figure 3. Utility curve with personal impact. 
The magnitude of the impact depends significantly on the exact nature of the dangerous activity why a person runs into a risk, that is, of the immediate cause of dying. An excessive aversion to some of these activities prevails such as cancer, nuclear power plants or air travels. There is a relative indifference to others such as traffic accidents. Therefore, the decision-maker should be inclined to eliminate these differences, by making his intentions clear, but he can hardly ignore them.

\section{Applications}

\subsection{Utility Functions}

If we transform the utility and the expected present value of income by their values by unit time, we can apply Equations (1) and (2) to solve some questions such as how much a person with monthly income of $w$ dollars would be willing to invest in a business that, if successful, would give him/her an additional income of $j$ monthly dollars in exchange for an investment of $g$ monthly dollars. Otherwise, he/she would only lose his/her investment with a 0.5 of probability. The quantity that the person would be willing to invest can be obtained by equating his/her current utility with the expected value of utilities that would result from the two possible states caused by the investment. Therefore, we can write:

$$
U(W)=0.5[U(w+j-g)+U(w-g)]
$$

By substituting Equation (1) into Equation (4), we get $\mathrm{e}^{-n_{1} k}=\mathrm{e}^{-n_{1} d}+1$, where $k=g / w_{\min }, d=j / w_{\min }, w_{\min }$ is the minimum monthly family income to survive. Henceforth, we are able to know the maximum amount $k$ given by $k=\frac{1}{n_{1}} \ln \left[2 /\left(\mathrm{e}^{-n_{1} d}+1\right)\right]$. Figure 4 shows a plot with the values of investment $k$ in terms of additional income $d$.

We follow the same procedure for the second utility function (Equation (2)) and we substitute Equation (2) into Equation (4) and we get

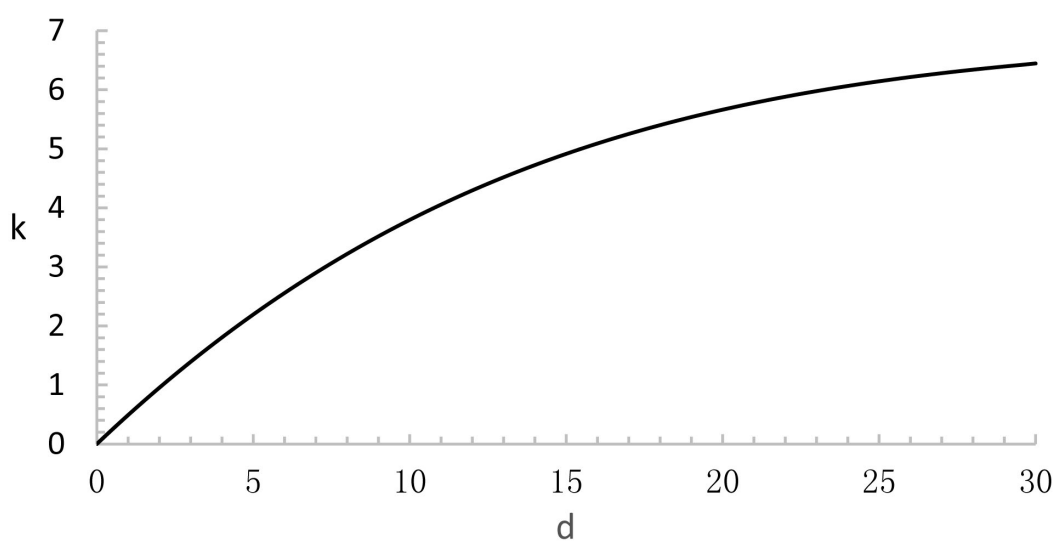

Figure 4. Additional income and investment using Equation (1). 
$\alpha \mathrm{e}^{-a \delta}\left[-2+\mathrm{e}^{a k}\left(\mathrm{e}^{-a d}+1\right)\right]=-\beta \mathrm{e}^{-b \delta}\left[-2+\mathrm{e}^{b k}\left(\mathrm{e}^{-b d}+1\right)\right]$, and again we find the value of the maximum amount $k$ using $\alpha=0.1, \beta=0.4$ and $\delta=10$. Figure 5 displays the corresponding graph.

In both cases, we must set an upper limit for the maximum amount $k$ so that $k \leq \delta$, because the person would not invest more than his/her net income (deducting from the total those he/she and his/her family would need). We observe in Figure 4 and Figure 5 that the shapes of the curves for both models are similar and that the maximum value is close to 7 and 5 for this example. If we have empirical data, the results obtained with the curves must coincide with the empirical results; otherwise, we would try new values of the parameters and repeat the analysis until we reconcile the results.

\subsection{Willingness Criteria}

Using the utility curve given in Equation (1) with $\alpha_{1}=0.5$, and $n_{1}=0.1$, we calculate $L$ from Equation (3). Figure 6 displays the factor $f=L / W$ for different values of $W / W_{\min }$. If the human capital approach assigns the value of $W$ to human life, the factor $f$ would be the factor by which one could multiply to get the value that an individual would assign to her/his life. The factor is always greater than one.

Using the utility curve given in Equation (2) with $\alpha=0.1, \beta=0.4, a=0.01$, and $b=0.18$, we compute $L$ from Equation (3). Figure 7 shows the factor $f=L / W$ for different values of $W / W_{\min }$, with the same meaning as in Figure 6 .

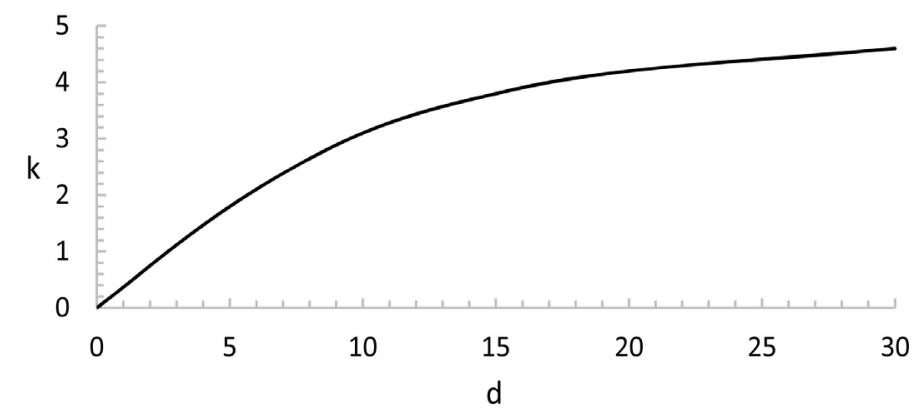

Figure 5. Additional income and investment using Equation (2).

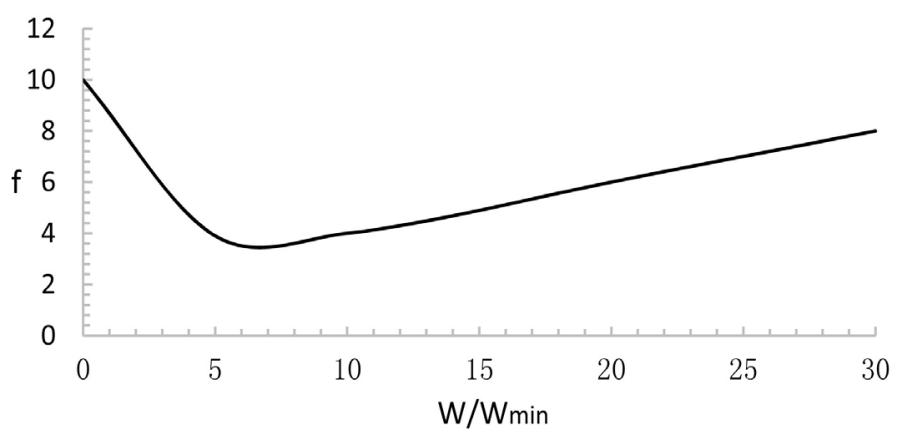

Figure 6. Factor for willingness criterion for small risks using Equation (1). 


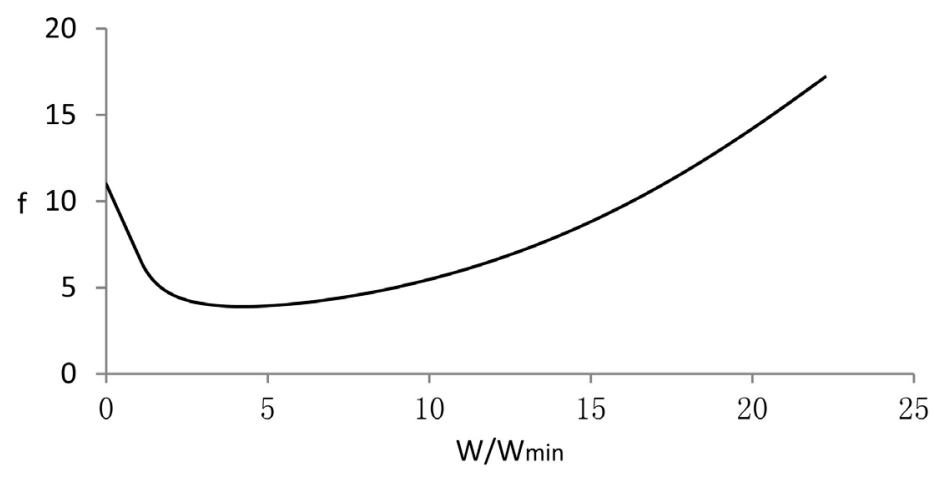

Figure 7. Factor for willingness criterion for small risks using Equation (2).

\subsection{Selection of Design Coefficients}

We have presented a method to assess how much society would be willing to invest in saving lives based on utility curves. The next step would be on how this approach can be used to select optimal seismic design parameters. A further discussion would be needed on how this approach would improve current seismic design initiatives (performance-based earthquake engineering (PBEE)) in order to promote a discussion for pragmatic implementation. The PBEE methodology has been explained in some guidelines such as VISION 2000 [14], FEMA 356 [15], and in some research papers [16] [17]. Vision 2000 [14] defines PBEE as design framework which ends in the required system performances at various intensity levels of seismic hazard. The desired performance levels to different hazard levels are determined based on the required type of buildings. FEMA 356 follows a similar framework as VISION 2000, describing differently both performances as well as hazard levels. The element deformation and force acceptability criteria related to the performance are defined for different structural and non-structural elements for static, dynamic, linear and nonlinear analysis. Porter [16] makes a summary of the PBEE approach being pursued by the Pacific Earthquake Engineering Research. The author uses a framework with four stages: hazard analysis, structural analysis, damage analysis and loss analysis. Hamburger [17] discusses guidelines of performance-based seismic design applicable to new buildings and upgrade of existing buildings. In this paper, performance can be expressed in terms of the probable financial, human, and occupancy interruption losses due to earthquake damage.

The optimum seismic design process for structures can be carried out by selecting a combination of criteria of seismic design, quality control, and strategies of repairing and maintenance, which lead to the minimum present value of the sum of initial costs and of costs that can occur during the life cycle of the system. The latter costs include those due to possible damage and failure as well as repairing and maintenance. Some recent studies in the literature deal with the initial costs and reconstruction cost for realistic design [18] [19] [20]. If the relationship between utility for society and the expected present value of its assets is taken as linear, a design will be approximately optimum when it minimizes the 
objective function given by initial cost and the expected present value of the losses due to earthquakes. Other decision rules can be employed to identify the optimum such as stochastic dominance [21], which includes the use of restrictions in the quality of social life, the socially tolerable risk, and attitudes toward risk of the decision-maker. The cumulative prospect theory [22] [23] includes several aspects of the human cognitive process and the perception of risk in decision making. For the sake of illustration, we will use here a simple conventional decision rule, which includes the calculated value as an additive term in the losses, in the formation of the objective function. This is explained bellow.

The approach for computing optimum seismic design parameters was first proposed by Rosenblueth [1] and Esteva [2]. They made the hypotheses that the process of occurrence of earthquakes is Poisson, the initial cost of a structure and the cost due to future earthquakes depend only on the intensity measure, and the system is rebuilt immediately after each failure. It is based on the optimization of the expected present value of the total cost $z(c)$, which includes the initial cost $x(c)$ of structures as well as the expected present value of the cost due to future earthquakes $y(c)$. Here $c$ is the seismic design coefficient. Thus, the following objective function is to be optimized.

$$
z(c)=x(c)+y(c)
$$

Based on work done by Whitman et al. [24], Grandori [25], Ferrito [26], Rosenblueth [4], and Vargas and Jara [27] it is reasonable to adopt the following expression for the initial cost of structures.

$$
\begin{aligned}
& x(c)=C_{1} \quad \text { if } c \leq c_{0} \\
& x(c)=\left[1+\alpha_{2}\left(c-c_{0}\right)^{\alpha_{3}}\right] C_{1} \quad \text { if } c>c_{0}
\end{aligned}
$$

where, if the structure is not designed to withstand earthquakes, $C_{1}$ would be its corresponding cost and $c_{0}$ would be its lateral resistance, $\alpha_{2}$ and $\alpha_{3}$ are constants.

The expected present value of the cost due to earthquakes $y(c)$ can be calculated as [2] [28] [29].

$$
y(c)=H(c) v(c) / \gamma
$$

where $v(c)$ is the exceedance rate of a seismic demand, $\gamma$ is the discount rate accounting for the value of the money in the future, and $H(c)$ is the expected present value of losses every time that an earthquake occurs. These losses are the consequences of the failure of the structure beyond its own construction cost, and are given by $x(c)+s(c)$ [30]. In most cases, $s(c)$ will be constant including the direct cost of direct physical damage and the cost of demolition and removal, but also cost of human life and injury so that $s(c)=s$ can be used.

Substituting Equation (6) and Equation (7) in Equation (5) and normalizing with respect to $C_{1}$ we find the expected present value of the total cost to be optimized given by: 


$$
z(c) / C_{1}=1+\alpha_{2}\left(c-c_{0}\right)^{\alpha_{3}}+\left[1+\alpha_{2}\left(c-c_{0}\right)^{\alpha_{3}}+s / C_{1}\right] v(c) / \gamma
$$

Application of Equation (8) is illustrated in a simple example by computing the optimum seismic design coefficient at a site with an exceedance rate of the seismic demand given by $v(c)=(0.001 / c)^{r}$, where $r$ depends on the site location, and takes the value of 1.5 for a low seismicity site [31]. Furthermore, we use $\alpha_{2}=0.5, \alpha_{3}=1.3, c_{0}=0.05, C_{1}=10^{5}$ [32] [33]. Table 1 shows different optimum seismic design coefficients for three cases where total wealth $W$ is 1,5 , and 15 times the minimum value necessary for surviving $W_{\min }$. The value corresponding to $s$ considers only the cost for human life and is computed by taking the human capital value of 45,000 US dollars obtained in García-Pérez [3] using data from Mexico, and then multiplied by the factor $f$ from Figure 7 corresponding to $W / W_{\min }$. The optimum values for seismic design coefficients are displayed in the last column.

The values of $c_{\text {opt }}$ from Table 1 are greater than those obtained by Ordaz et al. [31]. For example, for a low seismicity site, they report a value of $c=0.115$. We believe this difference is due to the approaches used. Ordaz et al. [31] establish a factor which accounts for indirect losses. This value was used by Ordaz et al. [34] as representative of the cost of indirect losses during the $1985 \mathrm{Mex}$ ico City Earthquake. In our case, we include directly the monetary value in the indirect losses. We also observe from Table 1 that $c_{o p t}$ does not increase as $W / W_{\min }$ increases. This is because the shape of the plot from Figure 7 near the origin is not straight. This is due to the incompleteness of parameters describing the utility curves. In building the utility curves we have assumed that the same relationships between income and utility per unit time are valid between the corresponding expected present values. We believe that, in general, this simplification does not introduce excessive errors, but maybe that it is not necessarily true for individual cases, especially when monthly income varies too much in function of time. However, even in this case, the shapes of these curves are quantitatively valid. It is also worthwhile noticing that the value of human life is not unique for the same person. It depends of the present value of its income in each instant and of the risk that the person is willing to be exposed. Moreover, in general conditions it depends also of other variables. However, it is not the intention here to produce utility curves that evolve with time, but it must be considered for future research. We need more research, especially in the choice of utility curves.

Table 1. Optimum seismic design coefficients.

\begin{tabular}{cccc}
\hline$W / W_{\min }$ & $f$ & $s\left(10^{5}\right)$ & $c_{\text {opt }}$ \\
\hline 1 & 6.85 & 3.1 & 0.17 \\
5 & 3.94 & 1.8 & 0.15 \\
15 & 8.81 & 4.0 & 0.18 \\
\hline
\end{tabular}


Besides exploring the choice of utility curves it is advisable to approach the problem by examining possible modifications in mortality rates. This will improve calculations on both the value in which society is willing to invest to preserve a life and seismic design coefficients. We can compute the value of the human life per unit time from an economic compensation or an expenditure per unit time which is associated with a modification in mortality rates. Then we obtain the value of the human life by transforming to a present value its value per unit time. The values computed in this way are those that a person would assign to his life. In the foregoing application, an attempt has been made to give at least a partial answer on how life saving cost can be used to select optimum seismic design coefficients. However, the incorporation of life saving cost into the objective function still requires further study, and a robust example for a real site is needed.

\section{Concluding Remarks}

In this study, we were interested in answering the question of how much society should invest to save lives. In order to do this, we discussed concepts of utility theory, felicity, individual and social values of life, and personal impact. Two utility curves in function of the wealth of an individual were under study. By using these curves, we were able to estimate the value of human life when dealing with small risks. An application was made to find the optimum seismic design at a low seismicity site. We conclude that more research is needed in order to assess the value of an intangible such as human life, especially in the choice of utility curves. The utility curves are functions of several variables for a specific person. Besides, even under stationary external circumstances, these curves evolve and change in time with the person's age. The shapes and the magnitudes of the maximum ordinates of these curves need to be well defined. It is important to establish the utilities coming from non-economic factors, in particular, the joy of the fact of being alive. It is necessary to carry out surveys over preferences between different alternatives and lotteries of conceptual type, and Delphi exercises; therefore, the values of the different parameters governing the utility curves can be established.

\section{Conflicts of Interest}

The authors declare no conflicts of interest regarding the publication of this paper.

\section{References}

[1] Rosenblueth, E. (1964) Closure to Probabilistic Design to Resist Earthquakes. Journal of the Engineering Mechanics Division, 90, Paper 4090.

[2] Esteva, L. (1968) Bases para la formulación de diseño sísmico. Ph.D. Thesis, Faculty of Engineering, UNAM, Mexico City.

[3] García-Pérez, J. (2012) The Value of Risk Reduction in Optimum Seismic Design. 
15th World Conference of Earthquake Engineering, Lisbon, 24-28 September, Vol. $11,8668-8676$.

[4] Rosenblueth, E. (1987) What Should We Do with Structural Reliabilities, Reliability and Risk Analysis in Civil Engineering. 5th International Conference on Applications of Statistics and Probability in Soil and Structural Engineering, Waterloo, Ontario, 24-34.

[5] Rosenblueth, E. (1992) The Social Value of Human Life in Earthquake Engineering. International Symposium on Earthquake Disaster Prevention, México, July, 185-197.

[6] Howard, R.A. (1979) Life and Death Decision Analysis Research. Report No. EES DA-79-2, Department of Engineering-Economic Systems, Stanford University, Stanford.

[7] Von Neumann, J. and Morgenstern, O. (1943) Theory of Games and Economic Behavior. 2nd Edition, Princeton University Press, Princeton.

[8] Keeney, R.L. and Raiffa, H. (1976) Decisions with Multiple Objectives: Preferences and Value Trade-Offs, John Wiley \& Sons, New York.

[9] Shepard, D. and Zeckhauser, R. (1984) Survival versus Consumption. Management Science, 30, 423-439. https://doi.org/10.1287/mnsc.30.4.423

[10] Viscusi, W.K. and Aldy, J.E. (2003) The Value of a Statistical Life: A Critical Review of Market Estimates Throughout the World. The Journal of Risk and Uncertainty, 27, 5-76. https://doi.org/10.3386/w9487

[11] Pandey, M.D. and Nathwani, J.S. (2004) Life Quality Index for the Estimation of Societal Willingness-to-Pay for Safety. Structural Safety, 26, 181-199.

https://doi.org/10.1016/j.strusafe.2003.05.001

[12] Starr, C. (1969) Societal Benefit versus Technological Risk, Science, 165, 1232-1248. https://doi.org/10.1126/science.165.3899.1232

[13] Starr, C. and Whipple, C. (1980) Risk of Risk Decisions, Science, 208, 1114-1119. https://doi.org/10.1126/science.208.4448.1114

[14] SEAOC Vision 2000 Committee (1995) Performance-Based Seismic Engineering. SEAOC, Sacramento.

[15] American Society of Civil Engineers (ASCE) (2000) Prestandard and Commentary for the Seismic Rehabilitation of Buildings. Report No. FEMA-356, Washington DC.

[16] Porter, K.A. (2003) An Overview of PEER's Performance-Based Earthquake Engineering Methodology. ICASP9, San Francisco, 6-9 July 2003, 1-8.

[17] Hamburger, R.O. (2004) Development of Next-Generation Performance-Based Seismic Design Guidelines, Performance-Based Seismic Design Concepts and Implementation. Proceedings of the International Workshop, Bled, 28 June-1 July 2004, PEER Report 2004/05, 89-100.

[18] Ang, A. and De Leon, D. (1997) Determination of Optimal Target Reliabilities for Design and Upgrading of Structures. Structural Safety, 19, 91-103.

https://doi.org/10.1016/S0167-4730(96)00029-X

[19] Esteva, L., Díaz-López, O. and Ismael, E. (2010) Seismic Vulnerability Functions of Multi-Storey Buildings and Applications. Structure and Infrastructure Engineering, 6, 3-16. https://doi.org/10.1080/15732470802663755

[20] Pozos-Estrada, A., Liu, T.J., Gómez, R. and Hong, H.P. (2016) Seismic Design and Importance Factor: Benefit/Cost for Overall Service Time versus per Unit Service Time. Structural Safety, 58, 40-51. https://doi.org/10.1016/j.strusafe.2015.08.005 
[21] Goda, K. and Hong, H.P. (2006) Optimal Seismic Design Considering Risk Attitude, Societal Tolerable Risk Level, and Life Quality Criterion. Journal of Structural Engineering, 132, 2007-2035. https://doi.org/10.1061/(ASCE)0733-9445(2006)132:12(2027)

[22] Tversky, A. and Kahneman, D. (1992) Advances in Prospect Theory: Cumulative Representation of Uncertainty. Risk Uncertainty, 5, 297-323. https://doi.org/10.1007/BF00122574

[23] Goda, K. and Hong, H.P. (2008) Implied Preference for Seismic Design Level and Earthquake and Earthquake Insurance. Risk Analysis, 28, 523-537. https://doi.org/10.1111/j.1539-6924.2008.01037.x

[24] Whitman, R.V., Biggs, J.M., Brennan III, J., Cornell, C.A., de Neufville, R.Y. and Vanmarcke, E. (1973) Summary of Methodology and Pilot Application, Seismic Decision Analysis. Report No. 9, Department of Civil Engineering, MIT, Cambridge, MA.

[25] Grandori, G. (1977) Seismic Zoning as a Problem of Optimization. 2nd International Conference on Structural Safety and Reliability, Munich, September 1977, 613-624.

[26] Ferrito, J.M. (1984) Economics of Seismic Design for New Buildings. Journal of Structural Engineering, 110, 2925-2937. https://doi.org/10.1061/(ASCE)0733-9445(1984)110:12(2925)

[27] Vargas, E. and Jara, J.M. (1989) Influencia del coeficiente sísmico de diseño en el costo de edificios con marcos de concreto, Memorias del VIII congreso nacional de ingeniería sísmica y VII congreso nacional de ingeniería estructural. Acapulco, Gro., nov.

[28] Rosenblueth, E. (1976) Optimum Design for Infrequent Disturbances. Journal of the Structural Division, 102, 1807-1825.

[29] Rackwitz, R. (2000) Optimization: The Basis of Code-Making and Reliability Verification. Structural Safety, 22, 27-60. https://doi.org/10.1016/S0167-4730(99)00037-5

[30] Rosenblueth, E. (1976b) Towards Optimum Design through Building Codes. Journal of the Structural Division, 102, 591-607.

[31] Ordaz, M., Salgado-Gálvez, A., Pérez-Rocha, L.E., Cardona, O. and Mena-Hernández, U. (2017) Optimum Earthquake Design Coefficients Based on Probabilistic Seismic Hazard Analyses, Theory and Applications. Earthquake Spectra, 33, 1455-1474. https://doi.org/10.1193/110116EQS189M

[32] García-Pérez, J., Castellanos, F. and Díaz, O. (2005) Occupancy Importance Factor in Earthquake Engineering. Engineering Structures, 27, 1625-1632. https://doi.org/10.1016/j.engstruct.2005.05.017

[33] García-Pérez, J. (2016) Expected Present Value of Losses in the Computation of Optimum Seismic Design Parameters. Engineering and Technology International Journal of Geological and Environmental Engineering, 10, 626-631.

[34] Ordaz, M., Jara, J.M. and Singh, S.K. (1989) Riesgo sísmico y espectros de diseño en el Estado de Guerrero, Joint report of the II-UNAM and the Seismic Investigation Center AC of the Javier Barrios Sierra Foundation. UNAM, Mexico City. 


\section{Appendix: Concepts and Notations}

Capital. Goods created by the process of investment that are capable of producing economic wealth.

Delphi Method. A way of obtaining forecasts of future developments.

Ethics. The study of the moral systems, where a moral system is a set of principles or norms whose acceptance leads to moral decisions.

Felicity. Utility in the sense of a logical scalar measure of the intensity of happiness.

Gross Domestic Product (GDP). The monetary value of all the finished goods and services produced within a country's borders in a specific time period.

Human Capital. The productive capacities of human beings as income-producing agents in the economy.

Present Value. The value today of a certain amount of money to be paid or received in the future.

Probability. The logical scalar measure of the intensity of certainty.

Utilitarianism. Ethical theory that establishes that the best action is the one that maximizes utility.

Utility. The logical scalar measure of the intensity of preference.

Willingness to Accept. The minimum amount of money an individual is willing to accept to abandon a good.

Willingness to Pay. The maximum amount an individual is willing to sacrifice to procure a good.

f. Factor by which one could multiply the human capital value to get the human life value.

$I_{p}$. Personal impact, after discounting the expected present value of the impact should the person not die as a consequence of the decision being analyzed.

$L$. Value in which society should invest to preserve a human life.

$U$. Expected present value of the utility per unit time.

$U_{\min }$. Utility corresponding to the survival value.

$U_{\max }$. Utility corresponding to the maximum wealth.

$W$. Expected present value of wealth.

$W_{\text {min }}$. Survival value of $W$. 